\title{
Technical nuances in the management of tuberculum sellae and diaphragma sellae meningiomas
}

\author{
Anil Nanda, M.D., M.P.H., Sudheer Ambekar, M.D., Vijayakumar Javalkar, M.D., \\ and Mayur Sharma, M.D.
}

Department of Neurosurgery, Louisiana State University Health Sciences Center, Shreveport, Louisiana

\begin{abstract}
Object. Tuberculum sellae meningiomas (TSMs) and diaphragma sellae meningiomas (DSMs) are challenging lesions to treat due to their proximity to neurovascular structures.

Methods. The authors reviewed the medical records of patients who underwent surgical excision of TSMs and DSMs from 1990 to 2013. They also describe the technical strategies used to minimize injury to the optic apparatus, vascular structures, and pituitary stalk.

Results. Twenty-four patients with TSM and 6 patients with DSM were included in the study. Seventy percent of the tumors were large $(\geq 5 \mathrm{~cm})$. The pterional approach was employed in most cases. Optic canal involvement was observed in 4 patients. Twenty-one patients (70\%) had visual dysfunction before surgery. At follow-up (median 18 months), visual improvement was noted in $10(47.6 \%)$ of 21 patients. Gross-total excision was achieved in 22 patients (91.6\%) with TSM and $5(83.3 \%)$ with DSM. At last follow-up, 28 patients (93.3\%) had a Glasgow Outcome Scale score of 5 . There were no deaths in this series.

Conclusions. Tuberculum and diaphragma sellae meningiomas present a unique subset of tumors due to their location. They can be safely excised with minimal morbidity and mortality using microsurgical techniques. Attention to technical details during surgery leads to greater respectability and superior visual outcome.

(http://thejns.org/doi/abs/10.3171/2013.10.FOCUS13350)
\end{abstract}

$\begin{array}{llclll}\begin{array}{l}\text { KEY WoRdS } \\ \text { visual outcome }\end{array} & \begin{array}{c}\text { tuberculum sellae } \\ \text { pterional }\end{array} & \bullet \quad \text { diaphragma sellae } & \bullet \quad \text { meningioma }\end{array}$

$\mathrm{M}$ ENINGIOMAS arising from the anterior cranial fossa floor constitute approximately $40 \%$ of all intracranial meningiomas, and tuberculum sellae meningiomas (TSMs) constitute approximately $25 \%$ of these tumors. ${ }^{11}$ They originate primarily from dura of the tuberculum sellae, chiasmatic sulcus, and limbus sphenoidale. Surgical excision of these tumors is a challenging endeavor due to the close association of the tumor with critical neurovascular structures such as the internal carotid artery (ICA), the anterior cerebral artery, anterior communicating artery (ACoA) complex and associated perforators, optic apparatus, and pituitary gland/ infundibular stalk. Although meningiomas arising from diaphragma sellae are usually combined with those arising from tuberculum sellae, certain differences in surgical management of these tumors exist.

Numerous open microsurgical and endoscopic approaches have been proposed to safely resect these tu-

\footnotetext{
Abbreviations used in this paper: $\mathrm{ACo} \mathrm{A}=$ anterior communicating artery; DSM = diaphragma sellae meningioma; GOS = Glasgow Outcome Scale; GTR = gross-total resection; ICA = internal carotid artery; TSM = tuberculum sellae meningioma.
}

mors while minimizing complications. ${ }^{1,6,16,18,25,36}$ Despite the variety of approaches, broadly, 3 groups of structures need to be managed appropriately during surgery for these tumors: the optic apparatus, vascular structures, and the pituitary stalk. The objective of this study was to critically analyze our series of surgically treated TSMs and diaphragma sellae meningiomas (DSMs) and review the technical nuances of surgery.

\section{Methods}

\section{Study Population}

After obtaining local institutional review board approval and in compliance with HIPAA regulations, we retrospectively reviewed the medical records, neuroimaging studies, and pathology reports of all patients who underwent resection of TSMs and DSMs by the senior author (A.N.) from 1990 to 2013. There were 24 patients with TSMs and 6 with DSMs. All patients were evaluated with Gd-enhanced MRI prior to surgery. For classification we divided the tumor size into 3 categories: small $(<3$ $\mathrm{cm})$, moderate $(3-5 \mathrm{~cm})$, and large $(>5 \mathrm{~cm})$. Patients with small tumors were chosen for surgery only if they were 
symptomatic or there was evidence of tumor growth on follow-up imaging. The patients were evaluated with Gdenhanced MRI in the postoperative period to assess the extent of resection. Gross-total resection was defined as Simpson Grade I or II removal confirmed by postoperative Gd-enhanced MRI. Follow-up data were available for all but 1 patient with DSM. Overall neurological outcome was measured according to the Glasgow Outcome Scale (GOS) rating at the most recent follow-up visit. Follow-up data of more than 6 months was available for 23 patients $(95.8 \%)$ with TSM and $3(50 \%)$ with DSM. We stratified the operative complications based on the origin of meningiomas, operative approach, and size of the meningiomas to look for any trends. Statistical analysis was performed with the SPSS software (version 21, IBM Inc.). Spearman correlation coefficients were calculated when necessary. Probability values less than 0.05 were considered statistically significant.

\section{Surgical Approach}

Most of the tumors in our series were resected via the standard pterional approach. The side of craniotomy depended upon the degree of visual deficit in both eyes and eccentric location or extension of the tumor. When the tumor was located in the midline, it was approached from the nondominant side. An anterior interhemispheric approach was used in 3 cases due to the more anterior and bilateral extension of the tumor. In our experience the pterional approach provides adequate exposure to most of the tumors located in the suprasellar region, and both transsylvian and lateral subfrontal routes may be used in accessing and dissecting the tumor. However, the lateral supraorbital approach may be suitable for small tumors and the anterior interhemispheric approach may be suitable for large tumors with bilateral and anterior extension. The advantages of the pterional approach over the other 2 approaches is that the CSF can be released from various cisterns causing brain relaxation, and the olfactory tracts can be preserved.

Management of the Optic Apparatus. Dissection of the tumor from the optic apparatus is an important step in the resection of TSM and DSM. Prior to surgery, displacement of the optic apparatus should be studied on T1weighted MRI. Depending upon whether the optic chiasm is prefixed, normally located, or postfixed, the tumor may displace the chiasm superiorly, posterior and superior, or posteriorly, respectively. The sylvian fissure was split widely and the cisterns opened to release the CSF and relax the brain. Following this procedure, the first step is identification of the ipsilateral optic nerve. The tumor is slowly dissected from the optic nerve with movements away from the nerve. The nerve may be thinned out and draped over the tumor along its superior surface. Care should be taken to develop an arachnoid plane around the tumor and avoid the use of cautery when dissecting close to the nerve so as to preserve its vascular supply. On the superior surface, the optic chiasm receives its blood supply from the pial plexus formed by the branches of anterior cerebral arteries and ACoAs, whereas on the inferior surface the branches of the superior hypophyseal artery supply the chiasm. ${ }^{2}$
The tumor is then devascularized from its attachment to the tuberculum sellae or the diaphragma sellae. If the tumor is too large to get to its attachment, partial piecemeal decompression may be done to obtain some space. The opposite optic nerve may be displaced superiorly or posteriorly, and the tumor should always be pulled away (inferiorly and medially) from the nerve within the arachnoid plane. Figure 1 illustrates a TSM and DSM and their displacement of the optic apparatus and vascular structures.

In patients with tumor extending into the optic canal, the optic canal is deroofed and opened by approximately 3-5 mm, and the tumor is dissected away from the nerve. The falciform ligament may also be cut to release the tension on the optic nerve. Additionally, anterior clinoidectomy may be performed to decompress the optic nerve and allow for dissection of the tumor from the nerve. We performed intradural anterior clinoidectomy in 2 patients in whom the tumor was extending into the optic canal. We advocate decompression of the nerves and maximal safe resection of the tumor as the goal of surgery, instead of radical resection at the cost of injuring the nerves.

Management of Vascular Structures. In addition to preservation and minimizing manipulation of the optic apparatus, preservation of vascular structures is paramount to successful resection. The ipsilateral ICA should be identified at the same time that the optic nerve is identified. The ACoA complex is located superior to the optic chiasm and is not usually involved by the tumor. However, the superior hypophyseal artery and the various perforators supplying the optic apparatus and the pituitary gland are located in close proximity to the tumor and should be identified and preserved. It is useful to assume that every vessel supplies normal structures unless the vessel enters the tumor, to avoid inadvertent sacrifice of vessels supplying normal brain. Again, dissection within the arachnoid plane of the tumor helps to preserve the normal vasculature. The tumor may be accessed through the caroticooptic and interoptic corridors. In DSMs the tumor is located under the chiasm and it is in these tumors that preservation of branches of the superior hypophyseal artery may be difficult.

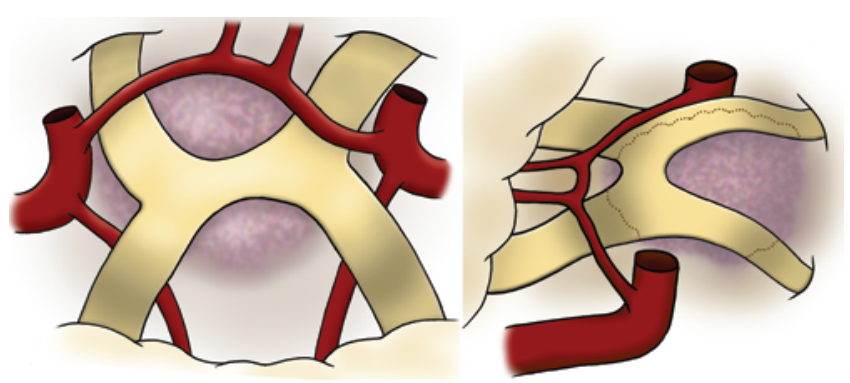

FIG. 1. Illustrations of a TSM (left) and DSM (right). The TSM displaces the optic chiasm and the vascular structures posteriorly and superiorly. The caroticooptic and interoptic corridors provide access to the lesion in most cases, depending upon the growth of the tumor. The DSM displaces the neurovascular structures superiorly and the pituitary stalk inferiorly. It is essential to decompress the tumor before dissecting it away from the optic chiasm to minimize tractional injury to these structures. Copyright Anil Nanda. Published with permission. 


\section{Management of tuberculum and diaphragma sellae meningiomas}

Management of the Pituitary Stalk. Identification and preservation of the pituitary stalk is important not only to prevent immediate postoperative electrolyte disturbances but also to prevent long-term morbidity. Depending upon the origin of the tumor, the pituitary stalk may be displaced anteriorly or posteriorly or not displaced at all. ${ }^{31}$ Stalk displacement and hormonal disturbances are more common in DSMs. The superior and inferior hypophyseal arteries supply the pituitary gland and the tumor should be dissected from the perforators to preserve gland function. Identification of the pituitary stalk comes later during surgery after identification of the neural and vascular structures.

\section{Results}

A total of 24 patients with TSM and 6 patients with DSM underwent resection. Seventy percent of the tumors $(\mathrm{n}=21)$ were large in size (maximum dimension $>5 \mathrm{~cm}$ ), $20 \%(\mathrm{n}=6)$ were between 3 and $5 \mathrm{~cm}$, and $10 \%(\mathrm{n}=3)$ were small in size $(<3 \mathrm{~cm})$. Optic canal involvement was observed in 4 patients $(13.3 \%)$. Twenty-one tumors (70\%) were at least $5 \mathrm{~cm}$. Gross-total excision was achieved in 22 patients $(91.6 \%)$ with TSM and $5(83.3 \%)$ with DSM. In 3 patients a small residue had to be left behind because of severe adherence of the tumor to the optic nerves due to prior surgery in 1 patient and optic canal involvement in the other 2 patients.

A total of 21 patients $(70 \%)$ had visual dysfunction before surgery in the form of diminished visual acuity and visual field deficit. Following surgery, improvement was noted in 9 patients $(42.9 \%)$. In 5 patients $(23.8 \%)$, no change was noted. In 7 patients $(33.3 \%)$ there was deterioration in vision following surgery (Table 1). Only 3 patients with normal preoperative vision developed newonset transient visual deterioration after surgery, which improved completely at discharge. Overall, at follow-up (median 18 months), visual improvement was noted in 10 $(47.6 \%)$ of the 21 patients with diminished vision. On univariate analysis, large tumor size $(>5 \mathrm{~cm})$ and optic canal involvement were significantly associated with visual deterioration ( $\mathrm{p}=0.01$ and 0.007 , respectively).

At last follow-up, 28 patients $(93.3 \%)$ had a GOS score of 5. There were no deaths in our series. Transient electrolyte disturbances were observed in 3 patients, all with DSMs. One patient with TSM developed a super- ficial operative site infection that responded well to antibiotic therapy. Recurrence of tumor was observed in 2 patients with TSM and none with DSM. Both patients underwent Gamma Knife surgery to the recurrent tumor with good control at last follow-up. Figures 2 and 3 show some preoperative, intraoperative, and postoperative images of patients with TSMs.

\section{Discussion}

In 1927, Holmes and Sargent ${ }^{24}$ described the chiasmal syndrome, a primary optic atrophy with bitemporal field defects in adult patients with normal sellae, which has been the characteristic presentation of these tumors. Often, the first manifestation of optic chiasmal compression is a bilateral superotemporal field defect. The temporal sequence of the manifestations of chiasmal syndrome, however, depends upon whether the chiasm is prefixed, normally located, or postfixed; for example, in a postfixed chiasm, the nasal fibers of the optic nerves are the first to be affected, leading to a bitemporal field defect. Irritation of the undersurface of the frontal lobes may lead to seizures in the patient. Large tumors may rarely lead to increased intracranial tension and obstructive hydrocephalus. Cushing and Eisenhardt published their seminal work in the book Meningiomas in $1938 .{ }^{8}$ Since then, many authors have used the term "suprasellar meningioma" loosely to describe these tumors. ${ }^{20,22,26,42}$ In 1995, Kinjo et al. classified DSMs into 3 types: 1) Type A, arising from the upper leaf of the diaphragma sellae anterior to the pituitary stalk; 2) Type B, arising from the upper leaf of the diaphragm sellae posterior to the pituitary stalk; and 3) Type C, arising from the inferior leaf of the diaphragm sellae. ${ }^{31}$ Type $\mathrm{C}$ tumors involve the sella and cause enlargement, mimicking a pituitary adenoma.

The surgical approach for TSMs and DSMs depends on multiple factors, such as tumor location, tumor size, overall neurological status, side of visual dysfunction, and surgeon preference. The most common surgical approaches described for these tumors are pterional, subfrontal, or a variant of these two. Sekhar et al. ${ }^{43}$ describe the extended frontal approaches to anterior skull base tumors. This approach is a modification of the transbasal approach of Derome with the addition of bilateral orbitofrontal or orbitofrontoethmoidal osteotomies tailored to improve the exposure of midline lesions, while mini-

TABLE 1: Salient features of patients who had visual worsening after surgery*

\begin{tabular}{cccccc}
\hline Case No. & Age $(\mathrm{yrs})$, Sex & Tumor Size $(\mathrm{cm})$ & Tumor Location & Optic Canal Involvement & Extent of Resection \\
\hline 3 & $45, \mathrm{M}$ & 3.5 & tuberculum sellae & yes & GTR \\
7 & $55, \mathrm{~F}$ & 5.5 & tuberculum sellae & no & GTR \\
8 & $58, \mathrm{~F}$ & 6.0 & diaphragma sellae & no & STR \\
10 & $78, \mathrm{M}$ & 4.0 & tuberculum sellae & yes & STR \\
13 & $45, \mathrm{M}$ & 5.2 & tuberculum sellae & no & GTR \\
17 & $46, \mathrm{M}$ & 2.9 & tuberculum sellae & yes & STR \\
18 & $43, \mathrm{~F}$ & 3.0 & tuberculum sellae & yes & GTR \\
\hline
\end{tabular}

* GTR = gross-total resection; STR = subtotal resection. 
A. Nanda et al.
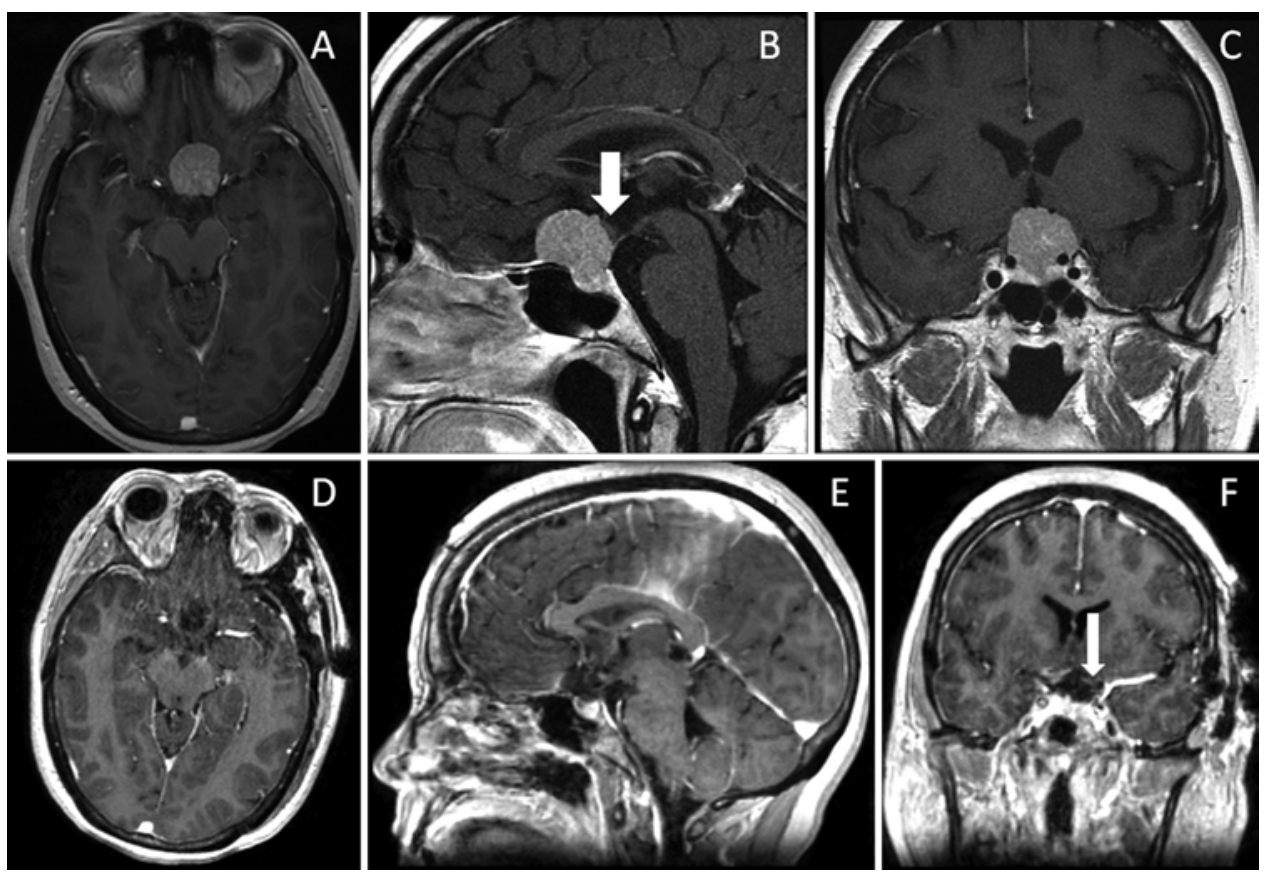

FIG. 2. Preoperative (A-C) and postoperative (D-F) axial, sagittal, and coronal Gd-enhanced MR images obtained in a patient with a TSM. The arrow in B shows the posterior and superior displacement of the optic chiasm. The arrow in F denotes the optic tract.

mizing the need for frontal lobe retraction. Arai et al. ${ }^{1}$ proposed a transcranial transsphenoidal approach for approaching TSMs. This, again, is a variant of the transbasal approach of Derome that allows better exposure of tumor inferomedially to the optic nerves. Other approaches previously described include the frontal sinus approach to olfactory groove meningiomas ${ }^{21}$ and the orbital roof craniotomy via an eyebrow incision..$^{28}$ In our experience, the pterional and anterior interhemispheric approaches were the main "workhorse" approaches; adjunctive skull base techniques may be used occasionally.

Preservation of optic function is an important aspect during surgery for TSMs and DSMs. The various factors to be considered while selecting the right surgical approach are the degree of visual deficits in both eyes, extension of the tumor, and involvement of the optic canal. The most difficult structure to identify during surgery is the ipsilateral optic nerve, and thus it has been
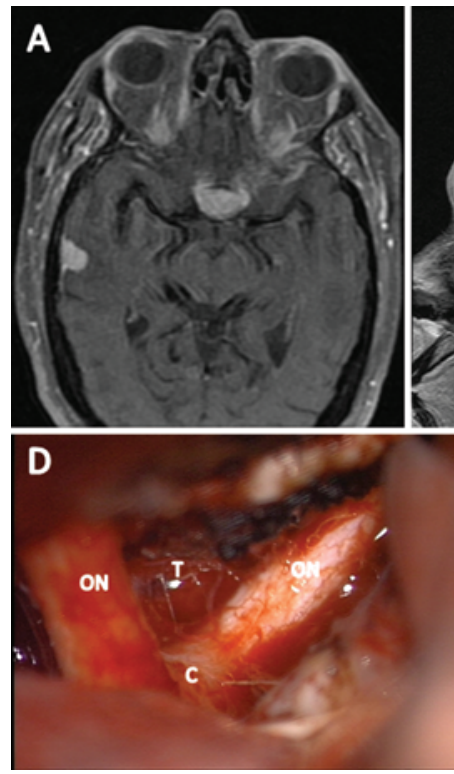
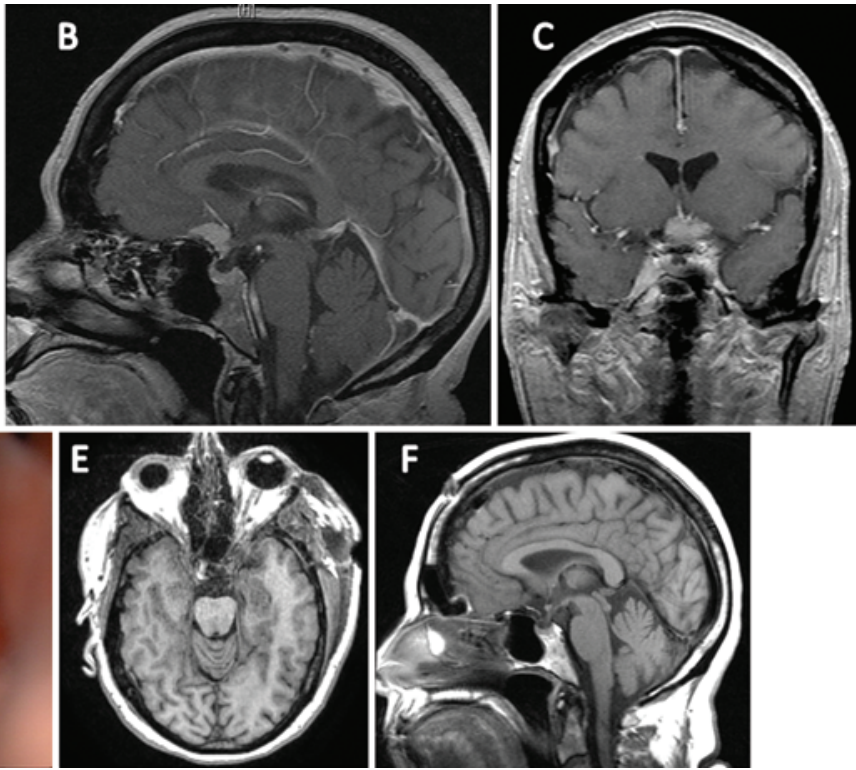

FIG. 3. Preoperative (A-C), intraoperative (D), and postoperative (E and F) images obtained in a patient with a TSM. A-C: Axial, sagittal, and coronal Gd-enhanced MR images. D: Intraoperative photograph. The tumor $(T)$ in this case is located predominantly in the interoptic space and has splayed the optic nerves (ONs) and displaced the optic chiasm (C) posteriorly. E and F: Axial and sagittal noncontrast-enhanced T1-weighted MR images. 


\section{Management of tuberculum and diaphragma sellae meningiomas}

advocated that the tumor be approached from the side on which the visual function is worse. ${ }^{3,30} \mathrm{~A}$ pitfall in this approach would be that the optic nerve may be extremely thinned out and appear pale on the side on which the visual function is worse. Hence, care should be taken while trying to identify the optic nerve. If the tumor is large, we advocate that the tumor be partially decompressed after identifying the optic nerve so that it becomes easy to dissect around the optic nerve. Use of Gelfoam (Pfizer) and Surgicel (Ethicon, Inc.) instead of thermal cautery is preferred while dissecting around the optic nerve to prevent thermal damage. We also advocate early dissection of the tumor around the optic nerve to decompress the nerve. Tumors extending into the optic canal present a formidable challenge to the surgeon. The goal of surgery in these cases should be to decompress the optic nerve and resect as much of the tumor as possible. The various techniques of decompressing the nerve include optic canal deroofing, cutting the falciform ligament, and anterior clinoidectomy. ${ }^{34,41}$ Both extradural and intradural clinoidectomy have been described in the decompression of the optic nerve. We prefer intradural clinoidectomy as it allows the surgeon to directly visualize the optic nerve and the tumor and have control over the area of bone being drilled and the ICA. Adequate irrigation during drilling is the key to minimizing thermal injury to the surrounding structures. In our experience, optic canal extension was found in 4 patients $(13.3 \%)$. In 2 patients, intradural clinoidectomy was performed in addition to deroofing the optic canal. On retrospective observation, of the 3 patients with normal preoperative visual function and who experienced transient visual deterioration in the postoperative period, adequate decompression of the tumor was probably not achieved before the dissection of the tumor from the optic nerve in 2 patients, thus causing excessive traction and ischemia of the optic nerves. In the third case, the reason for transient visual deterioration was unclear.

Encasement of vascular structures is another consideration during surgery. The ICA may be partially or completely encased. Preoperative T2-weighted MRI provides a clue to the degree of encasement or displacement of the artery. The ipsilateral ICA should be identified early in the surgery and care should be taken while dissecting the tumor off its medial surface, as most of the perforators arise from the medial and posterior surface of the artery. In most instances, despite the close relation of the tumor to the artery, there is a clearly defined arachnoid plane in between, which helps to dissect the tumor away. Use of a Cavitron ultrasonic aspirator helps to shave off the bulk of the tumor before dissecting the tumor from the artery. The ACoA complex lies superiorly to the tumor in most cases and may be in close proximity in large tumors. In our series, the ICA was partially encased in 9 cases (30\%) and completely encased in 2 cases (6.6\%). Over the years, the senior author has observed that identification of neurovascular structures early during surgery, avoidance of electrocautery while dissecting near the neurovascular structures, adequate decompression of the tumor before dissecting it off the optic nerves, and optimal use of the Cavitron ultrasonic aspirator are the key steps during surgery to achieve a superior outcome.
Diaphragma sellae meningiomas have a close relationship to the pituitary stalk. These tumors are more often associated with endocrine dysfunction and electrolyte abnormalities due to compression of the pituitary stalk. In most cases the stalk regains its normal function following resection. The stalk appears whitish when compared to the tumor and should be located early during surgery and preserved. Type C DSMs involving the sella often mimic pituitary adenomas. Bright enhancing sellar tumor on Gd-enhanced MRI should alert the physician to suspect a meningioma.

With the advent of keyhole and endoscopic approaches, an increasing number of TSMs are undergoing resection using these approaches. $7,9,12,17,19,27,29,33$ The endoscopic approaches are suitable for small- and medium-sized tumors located in the midline without involvement of the vascular structures and without significant superior or lateral extension. A significant extension of the tumor into the optic canal and laterally are contraindications to the endoscopic approaches. In a comparative study of the open and endoscopic approaches for the management of TSM, there was no significant difference in the quality of life of patients who underwent tumor resection using the open or endoscopic approaches. However, endoscopy had a higher CSF leak rate $(26.8 \%$ vs $3.5 \%$, p < 0.001) but a lower rate of injury to the optic apparatus (1.4\% vs $9.2 \%, \mathrm{p}<0.001)$ compared with a craniotomy. The 3 -year tumor recurrence rates were not statistically different $(\mathrm{p}$ $=0.529) .{ }^{14,15}$ Similarly, in another comparative study, open surgical approaches were associated with higher rates of gross-total resection (GTR) as compared with endoscopic approaches $(\mathrm{p}<0.05)$ for both olfactory groove meningioma and TSM. ${ }^{32}$ However, with the introduction of newer techniques such as nasoseptal flap, multilayer closure ("gasket seal") to achieve $<5 \%$ postoperative CSF leak, endoscopic endonasal approaches have come to be an alternative for midline ventral tumors with reduced morbidity.

Stereotactic radiosurgery is an effective method of controlling the growth of small- to medium-sized meningiomas of the anterior skull base. However, a more rapid improvement in endocrine function and visual disturbances is often achieved with microsurgical excision. ${ }^{37} \mathrm{In}$ fractionated stereotactic radiotherapy, the radiation dose is delivered in fractions over a time. It is believed that fractional delivery of radiation allows the normal tissue to repair between the fractionated doses. ${ }^{13}$ Various authors have successfully used fractionated radiotherapy either by stereotactic delivery or external beam therapy. $4,5,10,23,35,38-40,44-46$ The incidence of visual deterioration following fractionated stereotactic radiotherapy in one study was $3 \% .^{39}$

\section{Conclusions}

Tuberculum sellae meningiomas and DSMs present a unique subset of tumors due to their location. They can be safely excised with minimal morbidity and mortality using microsurgical techniques. Attention to technical details during surgery leads to greater resectability and superior visual outcome. 


\section{Disclosure}

The authors report no conflict of interest concerning the materials or methods used in this study or the findings specified in this paper.

Author contributions to the study and manuscript preparation include the following. Conception and design: Nanda, Javalkar. Acquisition of data: Nanda, Ambekar, Javalkar. Analysis and interpretation of data: Ambekar, Javalkar. Drafting the article: all authors. Critically revising the article: Nanda, Ambekar, Sharma. Reviewed submitted version of manuscript: all authors. Approved the final version of the manuscript on behalf of all authors: Nanda. Statistical analysis: Ambekar, Javalkar, Sharma. Administrative/ technical/material support: Nanda, Ambekar, Sharma. Study supervision: Nanda.

\section{References}

1. Arai H, Sato K, Okuda, Miyajima M, Hishii M, Nakanishi H, et al: Transcranial transsphenoidal approach for tuberculum sellae meningiomas. Acta Neurochir (Wien) 142:751-757, 2000

2. Blunt MJ, Steele EJ: The blood supply of the optic nerve and chiasma in man. J Anat 90:486-493, 1956

3. Bowers CA, Altay T, Couldwell WT: Surgical decision-making strategies in tuberculum sellae meningioma resection. Neurosurg Focus 30(5):E1, 2011

4. Brell M, Villà S, Teixidor P, Lucas A, Ferrán E, Marín S, et al: Fractionated stereotactic radiotherapy in the treatment of exclusive cavernous sinus meningioma: functional outcome, local control, and tolerance. Surg Neurol 65:28-34, 2006

5. Candish C, McKenzie M, Clark BG, Ma R, Lee R, Vollans E, et al: Stereotactic fractionated radiotherapy for the treatment of benign meningiomas. Int Radiat Oncol Biol Phys 66 Suppl:S3-S6, 2006

6. Ciric I, Rosenblatt S: Suprasellar meningiomas. Neurosurgery 49:1372-1377, 2001

7. Couldwell WT, Weiss MH, Rabb C, Liu JK, Apfelbaum RI, Fukushima T: Variations on the standard transsphenoidal approach to the sellar region, with emphasis on the extended approaches and parasellar approaches: surgical experience in 105 cases. Neurosurgery 55:539-550, 2004

8. Cushing H, Eisenhardt L: Suprasellar meningiomas, in Cushing $\mathrm{H}$ (ed): Meningiomas: Their Classification, Regional Behaviour, Life History, and Surgical End Results. Springfield, IL: Charles C Thomas, 1938, pp 224-249

9. de Divitiis E, Esposito F, Cappabianca P, Cavallo LM, de Divitiis $\mathrm{O}$, Esposito I: Endoscopic transnasal resection of anterior cranial fossa meningiomas. Neurosurg Focus 25(6):E8, 2008

10. Debus J, Wuendrich M, Pirzkall A, Hoess A, Schlegel W, Zuna I, et al: High efficacy of fractionated stereotactic radiotherapy of large base-of-skull meningiomas: long-term results. J Clin Oncol 19:3547-3553, 2001

11. DeMonte F: Surgical treatment of anterior basal meningiomas. J Neurooncol 29:239-248, 1996

12. Dusick JR, Esposito F, Kelly DF, Cohan P, DeSalles A, Becker DP, et al: The extended direct endonasal transsphenoidal approach for nonadenomatous suprasellar tumors. J Neurosurg 102:832-841, 2005

13. Elia AE, Shih HA, Loeffler JS: Stereotactic radiation treatment for benign meningiomas. Neurosurg Focus 23(4):E5, 2007

14. Eloy JA, Choudhry OJ, Shukla PA, Kuperan AB, Friedel ME, Liu JK: Nasoseptal flap repair after endoscopic transsellar versus expanded endonasal approaches: is there an increased risk of postoperative cerebrospinal fluid leak? Laryngoscope 122:1219-1225, 2012

15. Eloy JA, Kuperan AB, Choudhry OJ, Harirchian S, Liu JK: Efficacy of the pedicled nasoseptal flap without cerebrospinal fluid (CSF) diversion for repair of skull base defects: incidence of postoperative CSF leaks. Int Forum Allergy Rhinol 2:397-401, 2012
16. Fahlbusch R, Schott W: Pterional surgery of meningiomas of the tuberculum sellae and planum sphenoidale: surgical results with special consideration of ophthalmological and endocrinological outcomes. J Neurosurg 96:235-243, 2002

17. Fatemi N, Dusick JR, de Paiva Neto MA, Malkasian D, Kelly DF: Endonasal versus supraorbital keyhole removal of craniopharyngiomas and tuberculum sellae meningiomas. Neurosurgery 64 (5 Suppl 2):269-286, 2009

18. Fernandez-Miranda JC, Pinheiro-Nieto C, Gardner PA, Snyderman $\mathrm{CH}$ : Endoscopic endonasal approach for a tuberculum sellae meningioma. Neurosurg Focus Suppl 32(1):Video 8, 2012

19. Gardner PA, Kassam AB, Thomas A, Snyderman CH, Carrau RL, Mintz AH, et al: Endoscopic endonasal resection of anterior cranial base meningiomas. Neurosurgery 63:36-54, 2008

20. Guiot G, Montrieul B, Goutelle A, Comoy J, Langie S: [Retrochiasmatic suprasellar meningiomas.] Neurochirurgie 16: 273-285, $1970(\mathrm{Fr})$

21. Hallacq P, Moreau JJ, Fischer G, Beziat JL: [Frontal sinus approach to olfactory groove meningiomas.] Neurochirurgie 45:329-337, 1999 (Fr)

22. Hardy J, Robert F: [A meningioma of the sella turcica, subdiaphragmatic variety. Exeresis through the transsphenoidal route.] Neurochirurgie 15:535-543, 1969 (Fr)

23. Henzel M, Gross MW, Hamm K, Surber G, Kleinert G, Failing T, et al: Stereotactic radiotherapy of meningiomas: symptomatology, acute and late toxicity. Strahlenther Onkol 182: 382-388, 2006

24. Holmes G, Sargent P: Suprasellar endotheliomata. Brain 50: 518-537, 1927

25. Jane JA, McKissock W: Importance of failing vision in early diagnosis of suprasellar meningiomas. BMJ 2:5-7, 1962

26. Jefferson A, Azzam N: The suprasellar meningiomas: a review of 19 years' experience. Acta Neurochir Suppl (Wien) 28: 381-384, 1979

27. Jho HD: Endoscopic transsphenoidal surgery. J Neurooncol 54:187-195, 2001

28. Jho HD: Orbital roof craniotomy via an eyebrow incision: a simplified anterior skull base approach. Minim Invasive Neurosurg 40:91-97, 1997

29. Kabil MS, Shahinian HK: Application of the supraorbital endoscopic approach to tumors of the anterior cranial base. $\mathbf{J}$ Craniofac Surg 16:1070-1075, 2005

30. Kim TW, Jung S, Jung TY, Kim IY, Kang SS, Kim SH: Prognostic factors of postoperative visual outcomes in tuberculum sellae meningioma. Br J Neurosurg 22:231-234, 2008

31. Kinjo T, al-Mefty O, Ciric I: Diaphragma sellae meningiomas. Neurosurgery 36:1082-1092, 1995

32. Komotar RJ, Starke RM, Raper DM, Anand VK, Schwartz TH: Endoscopic endonasal versus open transcranial resection of anterior midline skull base meningiomas. World Neurosurg 77:713-724, 2012

33. Laufer I, Anand VK, Schwartz TH: Endoscopic, endonasal extended transsphenoidal, transplanum transtuberculum approach for resection of suprasellar lesions. J Neurosurg 106: 400-406, 2007

34. Lehmberg J, Krieg SM, Mueller B, Meyer B: Impact of anterior clinoidectomy on visual function after resection of meningiomas in and around the optic canal. Acta Neurochir (Wien) 155:1293-1299, 2013

35. Litré CF, Colin P, Noudel R, Peruzzi P, Bazin A, Sherpereel B, et al: Fractionated stereotactic radiotherapy treatment of cavernous sinus meningiomas: a study of 100 cases. Int J Radiat Oncol Biol Phys 74:1012-1017, 2009

36. Liu JK, Christiano LD, Patel SK, Tubbs RS, Eloy JA: Surgical nuances for removal of tuberculum sellae meningiomas with optic canal involvement using the endoscopic endonasal extended transsphenoidal transplanum transtuberculum approach. Neurosurg Focus 30(5):E2, 2011 


\section{Management of tuberculum and diaphragma sellae meningiomas}

37. Lunsford LD, Witt TC, Kondziolka D, Flickinger JC: Stereotactic radiosurgery of anterior skull base tumors. Clin Neurosurg 42:99-118, 1995

38. Metellus P, Regis J, Muracciole X, Fuentes S, Dufour H, Nanni I, et al: Evaluation of fractionated radiotherapy and gamma knife radiosurgery in cavernous sinus meningiomas: treatment strategy. Neurosurgery 57:873-886, 2005

39. Milker-Zabel S, Huber P, Schlegel W, Debus J, Zabel-du Bois A: Fractionated stereotactic radiation therapy in the management of primary optic nerve sheath meningiomas. J Neurooncol 94:419-424, 2009

40. Milker-Zabel S, Zabel A, Schulz-Ertner D, Schlegel W, Wannenmacher M, Debus J: Fractionated stereotactic radiotherapy in patients with benign or atypical intracranial meningioma: long-term experience and prognostic factors. Int J Radiat Oncol Biol Phys 61:809-816, 2005

41. Otani N, Muroi C, Yano H, Khan N, Pangalu A, Yonekawa Y: Surgical management of tuberculum sellae meningioma: role of selective extradural anterior clinoidectomy. Br J Neurosurg 20:129-138, 2006

42. Quest DO: Meningiomas: an update. Neurosurgery 3:219225,1978

43. Sekhar LN, Nanda A, Sen CN, Snyderman CN, Janecka IP:
The extended frontal approach to tumors of the anterior, middle, and posterior skull base. J Neurosurg 76:198-206, 1992

44. Selch MT, Ahn E, Laskari A, Lee SP, Agazaryan N, Solberg TD, et al: Stereotactic radiotherapy for treatment of cavernous sinus meningiomas. Int J Radiat Oncol Biol Phys 59:101111,2004

45. Torres RC, Frighetto L, De Salles AA, Goss B, Medin P, Solberg $\mathrm{T}$, et al: Radiosurgery and stereotactic radiotherapy for intracranial meningiomas. Neurosurg Focus 14(5):E5, 2003

46. Trippa F, Maranzano E, Costantini S, Giorni C: Hypofractionated stereotactic radiotherapy for intracranial meningiomas: preliminary results of a feasible trial. J Neurosurg Sci 53:7-11, 2009

Manuscript submitted August 15, 2013.

Accepted October 2, 2013.

Please include this information when citing this paper: DOI: 10.3171/2013.10.FOCUS13350.

Address correspondence to: Anil Nanda, M.D., M.P.H., Department of Neurosurgery, Louisiana State University Health Sciences Center, 1501 Kings Highway, PO Box 33932, Shreveport, LA 71130-3932. email: ananda@lsuhsc.edu. 